\title{
Two steps forward, one step back
}

\author{
The United Nations Environment Programme seems to \\ be faltering. Richard Sandbrook reports on the efforts \\ to deal with environmental problems on a global basis
}

\begin{abstract}
THE United Nations Environment 1 Programme (UNEP) has been having an uncomfortable time of late. Not only are funding problems now severely hampering the agency; there also appears to be increasing dissent about the work programme, both within and without the Secretariat. Nothing new in one sense for the UN; but at a time when many states are taking a new look at the UN in general following the recent "group of experts" report on its structure, and when its major donor, the United States, is severely pruning budgets, uncertainty in UNEP is not going to help its causes.
\end{abstract}

Initially UNEP was set up to carry through the 109 recommendations that came out of the UN Stockholm Conference on the Human Environment held in 1972. It was structured to consist of a Programme, which is the outline of the projects being tackled by UNEP, other UN agencies, national governments or non-governmental organisations; the Environment Fund, into which states make voluntary contributions; the Secretariat, consisting of 100 professional staff; and a Governing Council, composed of $58 \mathrm{UN}$ nations, which meets annually to review the programme and state of the fund. In addition, the executive director of UNEP chairs the Environment Coordination Board, which includes the heads of all other agencies in the UN family.

The fund started out with pledged contributions of $\$ 110$ million to carry it through its initial five years, and the energetic services of Maurice Strong, its first executive director. Strong had left his mark by the time he departed in January. He had tried hard to dispense with many of the usual UN nonsenses that slow up the whole business of running the existing UN agencies. Contracts were handed out in an almost commercial manner-rather as if a new research and development programme was in the making-and initially he circumvented the delaying process of UN recruitment by appointing consultants. The relationships between UNEP and non-governmental organisations, governments and other specialised agencies was-and still isfluid and open. The programme itself was neatly compartmentalised into priority levels and clear-cut objectives.

The author is at the International Institute for Environment and Development.
But UNEP had its fair share of teething problems too. Nairobi, the home of the programme, is not as accessible as the more "traditional" Geneva and New York, a particular disadvantage since the whole venture was set up partially to get existing outfits, such as the FAO, UNESCO and WHO, to cooperate together through the newly created Environment Coordination Board. $\mathrm{Mr}$ Strong and his team spent many months in the first three years commuting between the world's capitals for planning and promotional meetings. Back in Nairobi permanent staff recruitment was very slow, and the planning of programme projects became delayed. By the 1975 governing council meeting the fund was carrying forward large surpluses and certain states were complaining that not enough was being spent; UNEP had too much government money in its bank earning interest. Ironically this now forms the central excuse of the US Government for delaying their "promised" contributions (initially a $40 \%$ slice of the first five-year $\$ 110 \mathrm{~m}$ ).

\section{Changing attitudes}

Attitudes to the "environment problem" also began to change. Strong was above all a superb salesman who generated great interest and concern before Stockholm and immediately after it. In the early 1970s "the environment" was an important issue for western politicians. Now, some four years on, the environment issue is clearly not as politically pressing as it was; and, besides, many governments would argue that national pollution control is advancing rapidly. Initially the less developed world was very suspicious of the whole affair. Strong's answer was to promote "eco-development"--or "environment and development"- and a challenging declaration that united these themes was developed (the COCOYOC Declaration 1974). Gradually a constructive relationship built up between UNEP and the doubting Third World nations.

UNEP, however, has never been seen as a route for aid or technical assistance in the eyes of the major western donor countries-it is much more a "catalyst" (the most used word by delegates to the recent 1976 governing council) for sound environmental management. The idea of UNEP growing into an enlightened development agency with funding capabilities is certainly not acceptable. All this leaves the impression that the idea was potentialiy good; but for some the fashion is now passing, while for others UNEPs objectives are becoming less relevant. The current acting executive director, Dr Tolba, is nobly conducting a holding operation, but eventually the big issues will have to be resolved.

The first and major issue to be sorted out is the leadership question. Dr Tolba, an Egyptian, is due to leave this year; he could emerge as the new man from the horsetrading that goes on in New York, but the OECD countries and the South Americans may put up a challenge. Then there is the problem of replacing before the end of the year Mr Steadman, who runs the fund, and Mr Munro, who directs the programme. Both are available for office for only a short period. UNEP has always been beset with changes at the top, and this has created uncertainty all the way down.

\section{Financial problems}

The second issue is the state of the fund. The long lead time on project approval in the formative years has pushed the peak cash needs of UNEP toward the end of its first quinquennium. The cash requirements double between 1975 and 1976 to $\$ 40$ million and then slowly climb to an annual requirement of $\$ 55$ million by 1979 . (It is worth noting that the US Federal outlay in 1976 on pollution control and abatement was $\$ 683$ million for research and development activities alone.) Currently, the agency predicts a shortfall of some $\$ 10$ million to $\$ 12$ million a year from 1977 onwards. This figure is based on the revised pledges known at March 15 this year, some of which are well below those originally given when the agency was established. Commenting at the governing council in April, Tolba said that only $\$ 41$ million of the pledged $\$ 109$ million had so far been paid up, and some of that was in non-convertible currency from the USSR. The US was singled out as the major turncoat. Special visits to Moscow and probably the US are planned, but matters look bad: some 42 projects, Tolba reported, had already been delayed because of the cash crisis. Things could conceivably become a little easier for the agency after the US elections.

The third problem concerns the dream of Stockholm itself: how effective it will be in practical terms will in turn affect the long-term support UNEP gets. To date UNEP has successfully translated a few good ideas, such as that of the FAO for a Mediterranean pollution convention, into actual events (Barcelona, March 1976). They have also been closely involved in planning and funding the UN Water 
Conference (March 7, 1977, Argentina), the UN Deserts Conference (August 29, 1977, Nairobi), and the imminent UN Human Settlements Conference (May 31 to June 14, Vancouver). Much credit must go to UNEP for causing the latter two events to happen at all. All these conferences will help establish priorities and routes for aid and technical assistance in the coming years on pressing development fronts.

\section{Tasks remain}

But UN conferences can only assist in the evolution of "global environmental management"; all too often they seem to result in little more than high sounding cliches. Substantive tasks remain: the world's disappearing rainforests, the protection of the ever-growing num ber of threatened species, the chronically over-fished marine resources, rising levels of air and water pollution, to name a few. Whether or not resolutions which "urge" and reports which "chastise" are enough, UNEP is not in the final analysis going to be able to do very much on its own. It does not have the necessary expertise or financial base, and governments are not going to provide either. Division Three of UNEP, which handles environment and development issues, for example, recently suggested that a series of Third World alternative energy promotion centres be set up to provide practical and working alternatives to the current extremes of forest removal for firewood on the one hand and capital intensive, energy generating technologies on the other. Some delegations to the governing council clearly saw this as a subtle route to aid. One centre is enough for all to learn by, it was argued, and they were reduced in number to one. The idea of doing it regionally was ruled out.

Earthwatch is, in fact, the only significant functional task that UNEP is involved in apart from its conference support work. The remainder consists of overscanning some 150 projects to be carried out by other UN agencies, governments and institutions. These are organised into some eight priority areas, as follows: Human settlements and human health (1976 Budget $\$ 6.3$ million), Ecosystems research (1976 \$8.19 million), Environment and development (\$3.6 million), Oceans (\$3.6 million), Energy $(\$ 550,000)$, Natural disasters $(\$ 200,000)$, Environmental management (\$450.000), Environmental law $(\$ 300,000)$ and support functions (\$5.91 million). Earthwatch takes $\$ 3.4$ million this year.

Earthwatch consists of the International Referral System (IRS), the Global Environmental Monitoring Systems (GEMS), the International Register of Potentially Toxic Chemicals (IRPTC) and the Study of Outer Limits (climate change, risks to the ozone layer, increase in bioproductivity and weather modification). The aim of IRS is to have a global network of contacts in operation-a kind of environmental "yellow pages"- based on a data bank in Geneva. The system will consist of over 50 data focal points (to date only one is operational in the US; the Department of the Environment in Britain hopes to participate fully later this year). These feed in the basic data they have on the activities of various government departments, institutions and individuals in the environmental field. GEMS is trying to monitor key environmental variables on a global basis and thus fead to an assessment of the state of the environment in seven

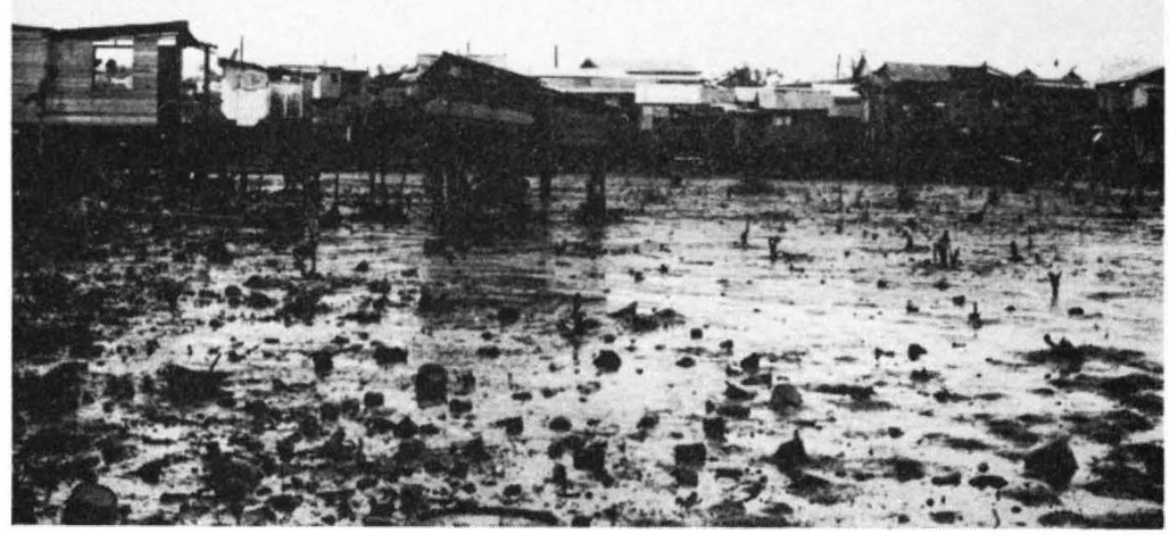

More than just an environmental problem: the litter and decay of a forgotten community (WHO photo) distinct areas. These include atmosphere monitoring in relation to climate, ocean monitoring, the depletion of renewable resources, natural disasters and human health. Throughout there is much emphasis on the concept of baseline studies.

\section{Coordination only}

UNEP is the first to point out that much of this monitoring is already done by other agencies and that its role is one of coordination only. There is, for example, UNESCO's Man and the Biosphere Programme; the work of the World Meteorological Organisation on climate; the FAO's work on land use, fisheries and soil structure; and, of course, many governments have their own monitoring programmes. It is hoped that variables will be monitored around the globe in a uniform and comparable way, and the data collated into central locations. But the problems in practice are going to be considerable. So-called baseline studies in the marine environment, for example, are notoriously difficult to carry out, and to many are of dubious scientific value anyway. To determine the quantities of various pollutant involved from atmospheric and land sources and their effect on the biological system is an almost impossible task; the state of the initial biological system is usually not known, is probably inherently variable, and the pathways of the pollutant far from clear.

It is thus apparent that UNEP structures are again in a state of wait and see. Until the financial and leadership questions are cleared up its future direction and style are unclear. At present, it is prevented from being the radical outfit that the Third World want by the priorities of its powerful western backers. Any confrontation with the real forces that lead to environmental degradation - inequality between nations and over-indulgent living as $\mathrm{Mr}$ Strong once put it-must wait. As the executive director stated in April, four years after Stockholm every country has come to grips with the fact that sustained development and meaningful growth were impossible without a commitment to preserve the environment and promote the rational use of resources. But if the Secretariat has adopted the principles of the brave new world, its major funding source has not. And yet, leaving the development issue aside, there is a clear need for UNEP simply to coordinate the significant effort being made toward the protection of the biosphere at a national, regional and international level. It has gone a long way in convincing governments and international agencies that this should be done. It would be a great pity if it were now denied the wherewithal to do it. 